\title{
Diagnostic of Drowning in Forensic Medicine
}

\author{
Audrey Farrugia and Bertrand Ludes \\ Institute of Legal Medicine, \\ 11 rue Humann 67085, \\ Strasbourg Cedex \\ France
}

\section{Introduction}

The diagnostic of drowning is described in the literature as one of the most difficult in the field of forensic medicine (Piette \& De letter, 2006). In fact, the external examination and the autopsy findings are in most of the cases not specific and the laboratory investigations are controversially appreciated by the scientific community. The main goal in this field is to differentiate a death by submersion from a immersion of a body. Death of a victim found in water should not always be related to drowning (Knight, 1991).

It is important to remind that the death by drowning is defined as a death due to submersion in a liquid and the mechanism in acute drowning is hypoxemia and irreversible cerebral anoxia (D.J. Di Maio \& V.J.M. Di Maio 1989).

\section{Physiopathology}

Considering the pathophysiology of human drowning, the role of mechanical airways obstruction and the washing out of alveoli surfactant as well as the shifts of fluid and electrolytes are still debated. In fact, several phases were described during the drowning process, first a breath-holding phase, followed by involuntary inspiration, gasping for air and loss of consciousness. The death is secondary of the development of cerebral hypoxia leading to irreversible brain damage. The duration of the phases is dependent on various factors, such as age, previous diseases, breath holding tolerance of the victims and the temperature of the water. Consciousness is usually lost within 3 minutes of submersion.

The inhaled water enters the alveolar spaces of the lungs and destroys the surfactant inducing pulmonary edema with the transudation of protein-rich fluid into the alveolar spaces. The surfactant washout decreases the lung compliance and ventilation-perfusion mismatch resulting to an hypoxemia secondary of non oxygenation of blood flowing through underventilated portions of the lung. A non cardiogenic pulmonary edema will result with secondary metabolic acidosis. This is the main pathophysiological mechanism of drowning and the fluid and electrolyte shifts are quite secondary. 
It was stated that fresh water is hypotonic and hyponatremic relative to blood inducing, after inhalation, a movementt of water from the alveoli into the blood and movement of sodium from the blood into the alveoli. These changes induce haemodilution, hypervolemia, hypnonatremia, hyperkalemia and haemolysis (Jeanmonod et al., 1992). As the sea water is very hypertonic relative to the blood, the water movement goes from blood into the alveoli and the electrolytes (sodium, chloride, magnesium) from the alveoli into the blood. The consequences of the sea water drowning should be haemoconcentration, hypovolemia and hypernatremia. The biochemical tests that proposed to assess the diagnostic of drowning are based on these fluids and electrolytes shifts. It is during the phases where water is penetrating from the alveoli into the blood circulation that particles like diatom passing through the alveolar-capillary interface before reaching internal organs.

A vagal reflex may be also induced by inhalation of water, it will increase peripheral airway resistance with pulmonary vasoconstriction, decreased lung compliance and reduction of ventilation - perfusion ratios (Ornato, 1986).

An intense stimulation of nerve endings at the skin, the mucosa of the ear drum, the pharynx or the larynx by cold water can lead to a cardiac reflex arrest. It was assumed that $10 \%$ of the drowned humans die after laryngospasm or breath-holding without actually aspirating fluid (Ludes \& Fornes, 2003). A discussion was also hold about the volumes of inhalated water and the effect on the circulation. In drowning, the inhalated volume of water can range, from relatively small to very large. It has been showed that small amount of water, particularly cold water, may induce vaso vagal reflex or cardiac arrest reflex. When great amounts of water are inhalated and pass through the alveolar-capillary interface and enter the circulation, the phenomenon of destruction of surfactant and of the alveoli architecture leads to asphyxia. During the entering of water into the blood stream, the diatoms present in the drowning fluid may reach the internal organs.

To establish the diagnosis of drowning it is of particular importance to correlate informations about the circumstances preceding the death, the past medical history of the victim if known, the circumstances of the body recovery from the water, the external examination, the autopsy findings and the results of the complementary analyses (histologic, biochemical, toxicological analyses and diatom test).

\section{Autopsy findings}

The majority of the autopsy findings are related to asphyxia and have no specific link to drowning. The signs of drowning depend on the delay in recovering the body and on the development of the putrefaction phenomenon which alter the positive signs of drowning. One of the signs of drowning would be large amounts of froth present around nostrils and mouth in freshly drowned bodies. This froth is also present in the upper and lower airways. Froth can also be observed in cases of edema of left ventricular failure but in drowning cases the volume of froth is generally much more abundant than in other origins.

It is admitted that lung weights are higher in drowning cases but it was shown that normal weights are possible in the drowning cases after cardiac arrest reflex or vaso vagal reflex. After water inhalation, the lungs may be over inflated, filling the thoracic cavity, generally water logged referred to as "emphysema aquosum". So the surfaces of lungs have a marbled appearance with dark red areas linked with collapsed alveoli, interspersed with more 
aerated tissues areas. The fluid is trapped in the lower airways and blocks the passive collapse of the bronchi that normally occurs after death. Subpleural bullae of emphysema, sometimes hemorrhagic may be found and are related to the rupture of the alveolar walls (Pounder, 2005). Even if these signs are mostly evocating of drowning, none of them is pathognomonic of water inhalation.

The body having sunk to the bottom of the site of drowning, will show a pattern of post mortem injuries such as post-mortem abrasion over the forehead, the prominent points of the face, the anterior trunk, the backs of the hands and the fronts of the lower legs. Injuries may also inflicted by passing watercraft in navigable waters by stumbling against rocks or by animal activities. Accidental or suicidal injuries due to the way the person falls or enters into the water may also be observed. Post-mortem injuries linked to the way of recovery of the body using ropes and hooks can also be seen. These kinds of post-mortem injuries can mimic ante-mortem wounds and the differentiation between ante and postmortem injuries is quite difficult because of the lack of the usual criteria of ante-mortem wounds.

It can also be found sand, silt, seashells and weeds in the airways, lungs, stomach and duodenum of drowned victims. If this material is fund in abundance within the alveoli, it can be related to an immersion during life as long as it concerns a freshly drowned body. This material may also enter the upper airways during the post-mortem immersion period and it is possible that small quantities may enter the oesophagus and stomach but it is unlikely that it will reach the alveoli to any significant extent if the post-mortem submersion is short.

One of the sign of immersion is skin maceration becoming visible after various time interval depending on the temperature of the immersion water. The skin becomes wrinkled, pale and sodden like a "washer woman's skin". These changes appear at the finger tips, palms, backs of the hands, and later, the soles. The next step is the detachment of the thick keratin of hands and feet which pull off in "glove and stoking fashion". Nails and hair become loosened after a few days. Other signs of immersion are cutis anserine and post-mortem distribution of hypostasis. The presence of mud, silt or sand on the body was described but has no diagnostic value.

\section{Complementary investigations}

\subsection{Histology}

The microscopic investigations must be performed on all the organs of non putrefied bodies in the aim to make the difference between a death by drowning and other causes of death. The lung examinations can show over-distension of the alveoli, thinning of the alveolar septa and compression with narrowing of the capillary network (Pounder, 2005).

The modifications in lungs are heterogeneous distributed and multiple sections must be performed to assess the diagnostic. In fact the microscopic appearance may be entirely normal in some part of the lungs.

Several staining techniques must be performed such as the staining for elastic fibers (orcein ) and reticulin fibers (Fornes et al., 1988 ; Ludes \& Fornes, 2003). The examination of other organs (brain, heart, liver) shows none specific histological changes indicative of hypoxia such as acute congestion and swelling of the capillary endothelia. 


\subsection{Biological tests}

The chemical changes in plasma after drowning were based on the fluid and electrolyte shifts after the penetration of either sea or fresh water in the alveoli and in the blood stream (Modell \& Davis, 1969). It was proposed the measurement of the specific gravity of blood, of the concentration of sodium, chloride and potassium. For the electrolytes, the diagnosis of drowning was based on changes of these electrolytes between the blood samples taken from the right versus left ventricle (Bray, 1985; Couteselinis \& Boukis 1976; Karkola \& Neittaanmaki, 1981). Such electrolyte shifts were described in many other causes of death and do not provide reliable evidence of drowning.

A special mention must be made for the blood strontium analysis. The toxicological analysis are performed to show the presence of medicaments or alcohol, taken before death in suicidal or accidental conditions and to determine the serum level of strontium which is described as a good parameter of drowning in sea water (Piette \& Timperman, 1989). In case of fresh water drowing, the water concentration of strontium must be higher than the serum concentration to be a valuable parameter in favour of drowning.

Authors such as Kane et al. $(1996,2000)$ and Nübel et al. (1997) proposed the detection by molecular biology techniques of the 16S rRNA subunits of ribosomal RNA for plankton detection in tissues samples indicating an active water inhalation and may assess the diagnostic of drowning. According to these authors, the sequence comparison of the variable regions of $16 \mathrm{~S}$ rRNA could provide sufficient information to allow the discrimination of both close and distant phylogenetic relationships.

Abe et al. (2003) and Suto et al. (2003) proposed the detection of chlorophyll-related genes of Euglena gracilis and Skeletonema costatum to identify plankton in the victim's tissues. It is important to emphasize that these methods give only qualitative results (He et al., 2008) but the quantitative approach can only be achieved by the diatom test which may also give an indication of the site of drowning.

In fact, diatoms can be considered as particles present in the submersion water which are inhalated during drowning and once in the blood stream which reach the closed organs. Under strict extraction and identification conditions, these particles are good markers of drowning.

Diatoms are unicellular algae belonging to the class of bacillariophycae which includes more than 15000 species living in fresh, brakish or sea water. The skeleton of these algae is called a frustule which is constituted by two valves fitting together to enclose the cytoplasm (Ludes \& Fornes, 2003) and made of hard silice.

Due to this hard silicaceous skeleton, diatoms can be recovered from putrefied or burnt tissues by either enzymatic or acid digestion (Ludes et al., 1994). The identification of these algae is based on the structure of their valves showing different symmetry allowing the distinction of two main groups namely the centric diatoms and the elongated or pennate diatoms.

After a long period of time where the use of the diatom test was very controversial due to false positive results linked to the presence of diatoms in closed organs of non drowned victims (Foged, 1983; Gylseth \& Mowe, 1979; Schellmann \& Sperl, 1979; Schneider, 1980, 1990; Schneider \& Kolb, 1969), it was stated by several authors that under strict defined 
analytical conditions this test could discriminate between drowning and none drowning cases (Auer \& Möttönen, 1988 ; Neidhard \& Greedyke, 1967; Peabody, 1977; Pollanen, 1997,1998; Pollanen et al., 1997). Auer \& Möttönen (1988) were one of the first authors to propose that 20 diatoms per microscope slide obtained from lung samples should be a sufficient concentration to exclude false positive due to contaminations. We also proposed qualitative and quantitative criteria for a positive drowning diagnostic with the diatom test.

For us, an analysis will be considered as positive when at least 20 diatoms are identified per $100 \mu \mathrm{l}$ of a pellet sediment extracted from a $2 \mathrm{~g}$ lung sample and the identification of more than 5 complete diatoms (with exclusion of fragments) per $100 \mu \mathrm{l}$ of a pellet sediment extracted from a $2 \mathrm{~g}$ tissue samples such as brain, kidney, liver and bone marrow. Bone marrow is described as a sanctuary organ and if diatoms reach this tissue, the diagnostic of drowning could be assessed.

In controlled samples belonging to non drowned victims, we newer find a number of diatoms above the fixed criteria. When diatoms were found in closed organs of drowned victims, the results in lung samples were in each case also above the 20 algae per $100 \mu \mathrm{l}$ pellet. To assess the diagnostic of drowning, it is of high importance to perform a qualitative analysis of the found diatoms and the comparison of the diatoms present in the closed organs and the microflora of the presumed site of drowning.

In this aim, water samples must be collected at the drowning site (two samples of $100 \mathrm{ml}$ ) as well as algae scraped from stones present in the water.

The samples are disposed in clean containers and the extraction and identification protocols on water and tissue samples were described by our group (Ludes et al., 1999). All reagents and glass containers must be checked for the absence of diatoms before use, and contamination from exogenous diatoms must be avoided by using diatom-free water and by protecting the organs during autopsy from the clothes of the victims and from the skin surface.

At each step of the analyses and the identification of diatoms, a potential contamination must be considered. This test cannot be proposed to assess the diagnostic of drowning in bathtub or in water containing very few algae, for example in iced water.

If water samples are not available, it is possible to compare the diatoms found in the organs with data collected in the rivers by a continuous water monitoring which can be set up by, for example, the Agencies in charge of the survey of water quality.

We set up a continuous water monitoring of the main rivers of our area (Ludes et al., 1996). Seasonal variations of the concentration of diatoms and the diatom profile are determined at a given month by the five most frequent species. The relative abundance of each diatom may also vary along the course of the river. So, the site of drowning may be determined by comparison between the water microflora with the diatoms found in the lungs. In fact, diatoms of more than $50-60 \mu \mathrm{m}$ in size rarely pass the alveoli-capillary barrier even after the rupture of the alveoli by the inhalation of water.

The diagnostic of drowning can be achieved when the qualitative analysis shows that the algae found in the organ belongs to the water microflora and the quantitative criteria are fulfilled (Hendey, 1973, 1980 ; Ludes et al., 1999). 


\section{Conclusion}

The diagnostic of drowning may be achieved after having considered all the forensic investigations performed in those cases, i.e: external examination, autopsy findings, histological and toxicological analysis, blood strontium determination, biochemical analysis and diatom test. The diatom test was still considered controversial by the by the literature but we defined qualitative and quantitative criteria which could exclude false positive results. It is of particular interest in case of putrefied bodies where the other investigations have failed.

\section{References}

Abe S, Suto M, Nakamura H, Gunji H, Hiraiwa K, Suzuki T, Itoh T, Kochi H, Hoshiai G (2003). A novel PCR method for identifying plankton in cases of death by drowning. Med. Sci. Law 43: 23-30.

Auer A, Möttönen M (1988). Diatoms and drowning. Z Rechtsmed 101: 87-98.

Bray M (1985). Chemical estimation of fresh water immersion intervals. Am J Forensic Med Pathol 61: 133-139.

Coutselinis A, Boukis D (1976). The estimation of magnesium concentration in cerebrospinal fluid as a method of ,drowning diagnosis in seawater. Forensic Sci 7: 109-111.

Davis J (1986). Bodies found in the water: an investigative approach. Am. J. Forensic Med Pathol 7: 281-287.

DiMaio DJ, DiMaio VJM (1989) Drowning. In: DiMaio DJ, DiMaio VJM, eds. Forensic pathology. Elsevier, Amsterdam pp. 357-365.

Foged N (1983). Diatoms and drowning. Once more. Forensic Sci Int 21: 153-159.

Fornes P, Pepin G, Heudes D, Lecomte D (1988) Diagnosis of drowning by computerassisted histomorphometry of lungs with blood strontium determination. J Forensic Sci 43(3): 772-776.

Gylseth B, Mowe G (1979). Diatoms in the lung tissue. Lancet 29: 1375.

He F, Huang D, Liu L, Shu X, Yin H, Li X (2008). A novel PCR - DGGE - based Method for Identification Plankton $165 \mathrm{r}$ DNA for the Diagnosis of Drowning. Forensic Sci Int $176: 152-156$.

Hendey NI (1973). The diagnosis value of diatoms in the cases of drowning. Med Sci Law 13(1): 23-34.

Hendey NI (1980). Letter to the Editor, diatoms and drowning - A review. Med Sci Law 20(4): 289.

Jeanmonod R, Staub Ch, Mermillod B (1992). The reliability of cardiac haemodilution as a diagnostic test of drowning. Forensic Sci Int 52: 171-180.

Kane M, Fukunaga T, Maeda H, Nishi K. (2000). Phylogenetic analysis of picoplankton in Lake Biwa and application to legal medicine. Electrophoresis 21: 351-354.

Kane M, Fukunaga T, Maeda H, Nishi K. (1996). The detection of picoplankton 16S rDNA in case of drowning. Int. J. Leg. Med. 108: 323-326.

Karkola K, Neittaanmaki H (1981). Diagnosis of drowning by investigation of left heart blood. Forensic Sci Int 18: 149-153. 
Knight B (1991). Immersion deaths. In: Knight B, ed. Forensic Pathology, E.Arnold, London pp. 360-374.

Ludes B, Fornes P. (2003). Drowning in : Forensic Medicine : Clinical and Pathological Aspects. Payne-James J, Busuttil A, Smock W eds, Greenwich Medical Media, pp 247-257.

Ludes B, Coste M, North N, Doray S, Tracqui A, Kintz P (1999). Diatom analysis in victim's tissues as an indicator of the site of drowning. Int J Legal Med 112: 163-166.

Ludes B, Coste M, Tracqui A, Mangin P (1996) Continuous river monitoring of the diatoms in die diagnosis of drowning. J Forensic Sci 41(3): 425-428.

Ludes B, Quantin S, Coste M, Mangin P (1994). Application of a simple enzymatic digestion method for diatom detection in the diagnosis of drowning in putrefied corpses by diatom analysis. Int J Med 107: 37-41.

Modell JH, Davis JH (1969). Electrolyte changes in human drowning victims. Anesthesiology 30: 414-417.

Neidhart DA, Greedyke RM (1967). The significance of diatom demonstration in the diagnosis of death by drowning. Am J Clin Pathol 48(4): 377-382.

Nübel U, Garcia-Pichel F, Muyzer G (1997). PCR primers to amplify 16S rRNA genes from cyanobacteria. Appl. Environ. Microbiol 63: 3327-3332.

Ornato JP (1986). The resuscitation of near-drowning victims. JAMA 256: 75-77.

Peabody AJ (1977). Diatom in Forensic Science. J Forensic Soc 17: 81-87.

Piette M, Timperman J (1989). Serum strontium estimation as a medico-legal diagnostic indicator of drowning. Med Sci Law 29: 162-171.

Piette M.H.A, De Letter E.A (2006). Drowning : still a difficult autopsy diagnosis. Forensic Sci. Int 163 1-9.

Pollanen MS (1997). The diagnosis value of the diatom test for drowning, II. Validity: analysis of diatoms in bone marrow and drowning medium. J Forensic Sci 42(2): 286-290.

Pollanen MS (1998). Forensic diatomology and drowning. Elsevier (Amsterdam) ed.

Pollanen MS, Cheug C, Chiasson DA (1997). The diagnosis value of the diatom test for drowning, I. Utility: a retrospective analysis of 771 cases of drowning in Ontario, Canada. J Forensic Sci 42(2): 281-285.

Pounder DJ (2005). Drowning in: Encyclopedia of Forensic and Legal Medicine. PayneJames J, Byard RW, Corey TS, Henderson C eds, Elsevier Academic Press pp 227232.

Schellmann B, Sperl W (1979). Nachweis im Knochenmark (Femur) Nichtertrunkener. Z Rechtsmed 83: 319-324.

Schneider V (1980). Detection of diatoms in the bone marrow of non-drowning victims. Z Rechtsmed 85(4): 315-317.

Schneider V (1990). Zur Diatomeen Assoziations Methode: Alt-bekannte "neu" entdeckt? Z Kriminalistik 44: 461.

Schneider V, Kolb KH (1969). Uber den nachweis von radioaktiv markierten Diatomeen in den Organen in den Organen. Beitr Gerichd Med 25: 158-164. 
Suto M, Abe S, Nakamura H, Suzuki T, Itoh T, Kocbi H, Hoshiai G, Hiraiwa K (2003). Phytoplankton gene detection in drowned rabbits. Leg. Med. 5: S142S144. 


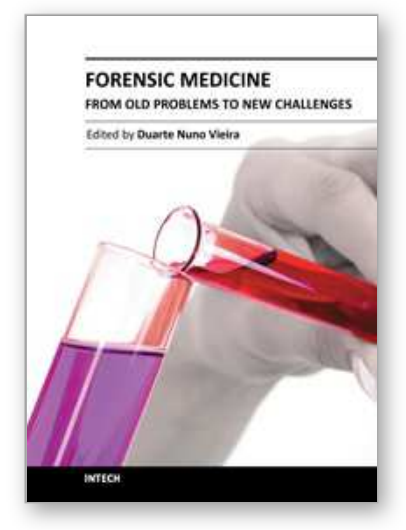

\author{
Forensic Medicine - From Old Problems to New Challenges \\ Edited by Prof. Duarte Nuno Vieira
}

ISBN 978-953-307-262-3

Hard cover, 382 pages

Publisher InTech

Published online 12, September, 2011

Published in print edition September, 2011

Forensic medicine is a continuously evolving science that is constantly being updated and improved, not only as a result of technological and scientific advances (which bring almost immediate repercussions) but also because of developments in the social and legal spheres. This book contains innovative perspectives and approaches to classic topics and problems in forensic medicine, offering reflections about the potential and limits of emerging areas in forensic expert research; it transmits the experience of some countries in the domain of cutting-edge expert intervention, and shows how research in other fields of knowledge may have very relevant implications for this practice.

\title{
How to reference
}

In order to correctly reference this scholarly work, feel free to copy and paste the following:

Audrey Farrugia and Bertrand Ludes (2011). Diagnostic of Drowning in Forensic Medicine, Forensic Medicine - From Old Problems to New Challenges, Prof. Duarte Nuno Vieira (Ed.), ISBN: 978-953-307-262-3, InTech, Available from: http://www.intechopen.com/books/forensic-medicine-from-old-problems-to-newchallenges/diagnostic-of-drowning-in-forensic-medicine

\section{INTECH}

open science | open minds

\section{InTech Europe}

University Campus STeP Ri

Slavka Krautzeka 83/A

51000 Rijeka, Croatia

Phone: +385 (51) 770447

Fax: +385 (51) 686166

www.intechopen.com

\section{InTech China}

Unit 405, Office Block, Hotel Equatorial Shanghai

No.65, Yan An Road (West), Shanghai, 200040, China

中国上海市延安西路65号上海国际贵都大饭店办公楼 405 单元

Phone: $+86-21-62489820$

Fax: $+86-21-62489821$ 
(C) 2011 The Author(s). Licensee IntechOpen. This chapter is distributed under the terms of the Creative Commons Attribution-NonCommercialShareAlike-3.0 License, which permits use, distribution and reproduction for non-commercial purposes, provided the original is properly cited and derivative works building on this content are distributed under the same license. 